\title{
Assessment of Physio-Chemical Parameters of Well Water of Katol Nagpur
}

\author{
Sheikh Juber Sheikh Jabbar Sheikh ${ }^{1}$, Dr.Arif Khan ${ }^{2}$ \\ ${ }^{I}$ M.Tech student, (IV sem, VEnvironmental Engg., Nuva College of Engineering \& technology, Nagpur, Maharashtra(India). \\ ${ }^{2}$ Principal, Nuva College of Engineering \& technology, Nagpur.
}

\begin{abstract}
Physio-chemical analysis of Well Water of Katol Tehsil, District Nagpur has been studied, All the samples were analyzed to assess the water quality parameters like Temperature, Physical appearance, Odor, Turbidity,. The discharge of industrial effluents without prior treatment has led to the pollution of well water bodies. The present study determined the physicochemical characteristics ( $\mathrm{pH}$, electrical conductivity, total dissolved solids, total suspended solids, total solids, carbonate, bicarbonate, alkalinity, phosphate, nitrate, temperature, chloride and turbidity) and concentrations of selected heavy metals (cadmium, copper, chromium, nickel and lead) of water samples from eleven well water bodies in and around Katol. The values of the physicochemical parameters indicate that most of the well water bodies are heavily polluted with the level of pollution, increasing over the period. Out of the five heavy metals analysed, the well water bodies were mainly polluted with copper, cadmium, and lead. A systematic study has been carried out to assess the water quality index of wells in Katol Tehsil. Some water samples from five sampling stations were collected and analysed for physio-chemical parameters (Temp, velocity, $\mathrm{pH}$, dissolved oxygen, free $\mathrm{CO} 2$, C.O.D., B.O.D., Carbonate, Bicarbonate, total alkalinity, hardness, turbidity, calcium, magnesium, sodium, potassium, nitrate, phosphate, chloride, sulphate, electrical conductivity, total dissolved solids and total suspended solids.). It was found that most of the parameters are within the permissible limit as described by W.H.O.
\end{abstract}

Keywords: Water pollution, well water, physic-chemical analysis, Water quality index, portability, Dissolved Oxygen,.

\section{INTRODUCTION}

W ater is next to oxygen as being essential for life. People can survive days, weeks, or even longer without food, but only about few days without water. Water is one of the essential commodities of everyday life and is placed in position just after air. Although it is nature's abundant gift but most of it is present in oceans $(97 \%)$ and in the icebergs in the Polar Regions $(2 \%)$ which are of no use for utilization and the remaining (1\%) of all earth's water, which is available in lake, rivers and underground for utilization. Also this available water which is found in nature is not $\mathrm{H} 2 \mathrm{O}$ alone. Hence it can be considered as a separate entity and can be expressed as (H2 O $+\mathrm{X})$, where ' $\mathrm{X}$ ' is measurable and controlled. More over this available water is also contaminating day by day by different human activities. These pollutions are mainly due to rise standard of living, urbanization, expansion of agriculture and increase of population. The population of India has exceeded thousand million today and also the urban population more than four million, which indicate the large demand of water for domestic purposes. The ill health in the developing and under developing countries is mainly due to lack of safe drinking water. Drinking water is never pure. Water naturally contains minerals and microorganisms from the rocks, air and soil with which it comes in contact. Many more substances human activity can add. But drinking water does not need to be safe to be pure. In fact, some dissolved minerals can be beneficial to health in water. For example, the National Research Council (National Academy of Sciences) states that drinking water containing dissolved magnesium \& calcium generally contributes a small amount toward magnesium \& calcium human dietary needs. Fluoride, either added or naturally occurring to the water supply, can help protect against tooth decay. water is safe or not will depend on impurities which are present and its amount(1) Whether the drinking. A survey conducted by WHO in 1975 on community water supplies revealed the fact that in India while $80 \%$ of the population in 
urban areas had access to community water supplies and only $18 \%$ of the rural population had access to safe water reasonable. The present paper deals with the drinking water quality analysis of some wells of Katol town, Nagpur (India). The results are compared with W.H.O. and I.S.I Standard.

\section{II- METHODOLOGY}

\subsection{Sampling Sites:}

Katol is a Tehsil place in district Nagpur (Maharashtra).The Katol Town is surrounded by industrial area. W1 :- Well Water Near Mahadev Mandir (ward no.1).W2- Well Water Near Baemase House (ward no.2).W3 :- Well Water Near shri Tulsiram Shade House (ward no.5).W4 :- Well Water Near shri Shabhrate sabhagru (ward no.10).W5 :- Well Water Near Gawhane Layout (ward no.13).W6 :- Well Water Near Hore Layout (ward no.13).W7 :- Well Water Near Shri Mahendra Shende House (ward no.14).W8 :- Well Water Near Karedi Vikry Society (ward no.5).W9 :- Well Water Near Radhika Hospital \& Panchkrma centre (ward no.5).W10 :- Well Water Near Mahanubhav Mandir (ward no.6).W11 :- Well Water Near Katol Garden (ward no.6).W12 :- Well Water From Shri Shabhrate House. (ward no.10).W13 :- Well Water From Shri Amrutlalji Tull House (ward no.7).W14 :- Well Water Backside of Gurudwara (ward no.7).W15 :- Well Water from Masjid (ward no.8).W16 :- Well Water from R.R.Ramavat House (ward no.9).W17 :- Well Water From Shri Suresh Meshram House. (ward no.9).W18 :- Well Water From Shri Rahul Jains House (ward no.10).W19 :- Well Water From Shri Lalit Waghmare House (ward no.10).W20 :- Well Water Backside Ashoka Dhaba \& Savaji Resturant (ward no.11).W21 :- Well Water from The Perfect Lawn (ward no.11).W22 :- Well Water From Gajanan Mandir. (ward no.12).W23 :- Well Water From Hanuman Mandir,Ispat Nagar (ward no.12).W24 :- Well Water From Shri Roshan Gupta House (ward no.13).W25 :- Well Water from Kolbaswami Mandir (ward no.13).W26 :- Well Water Near Shende Kirana Store (ward no.14).W27 :- Well Water Near Bethal Church. (ward no.14).W28 :- Well Water Near New Budhwari Bazar (ward no.15).W29 :- Well Water From Agriculture Produce Market Community (ward no.15).W30 :- Well Water from Saurabh Mankar House (ward no.16). The methods applied for analysis are usually followed as prescribed by NEERI (1986)

\section{III-RESULT AND DISCUSSION:}

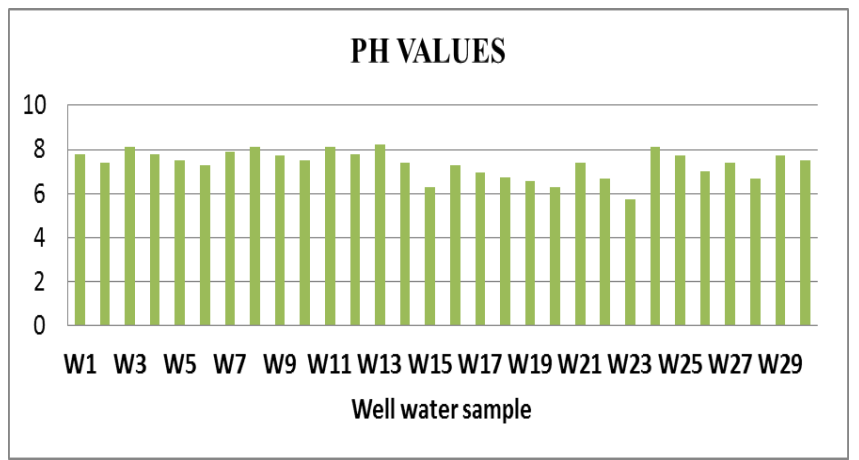

$\mathrm{pH}$ range of 6.5 to 8.5 is generally accepted as per guide line suggested by W.H.O (1984)(3). From the Fig.1,it is found that the $\mathrm{pH}$ value of water sample within the study area ranged from 7.4 to 8.2 which shows that the water sample was observed to be slightly alkaline it's known that $\mathrm{pH}$ of water doesn't cause any sever hazard . The desirable limit of Total Alkalinity is $200 \mathrm{mg} / \mathrm{l}$. the worth of Alkalinity of ground water varied from 270 to $315 \mathrm{mg} / \mathrm{l}$ as shown in Fig.2.

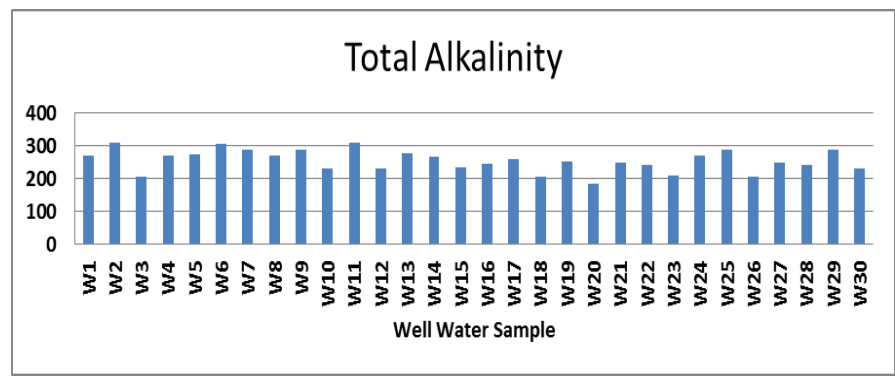

The desirable limit of total hardness of drinking water according to Indian standard institute (ISI 10500)(4) is $300 \mathrm{mg} / \mathrm{L}$, in surveyed area its value in ground water varied from 510 to $1640 \mathrm{mg} / \mathrm{L}$. From the Fig. 3 it is found that permanent hardness in ground water sample varied from 140 to $1390 \mathrm{mg} / \mathrm{L}$.

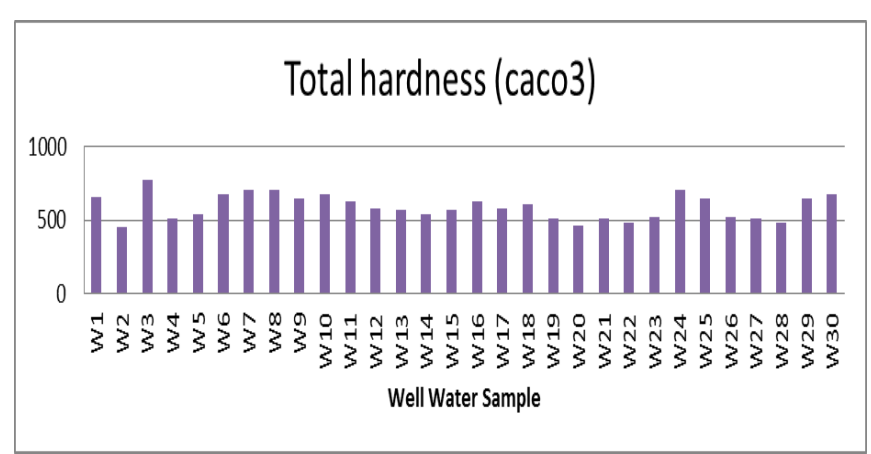

Sodium and Potassium are termed as alkali metals, sodium is abundant in water because of its compound are readily soluble in ground water, it is generally found to be $>5 \mathrm{mg} / 1$. Ground water pollution by sodium salt is an unavoidable phenomenon 
cause from the return flow of irrigation and disposal of Industrial and Urban waste. In large concentration it may affect a person with a Cardiac deficiency. From the Fig. 4 it is found that, the values of Sodium in surveyed area varied from 140 to $230 \mathrm{mg} / \mathrm{L}$

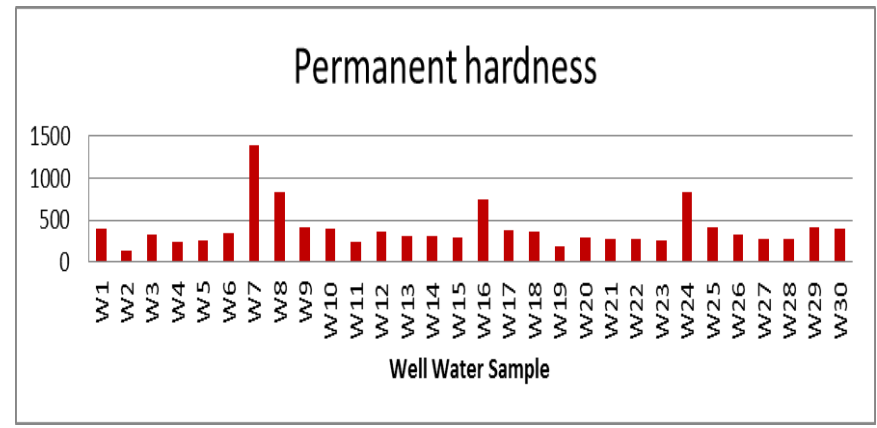

The chloride is troublesome in irrigation water and harmful for aquatic life. The concentration of Nitrate (as an NO3) for supplied water over $100 \mathrm{mg} / \mathrm{l}$ causes mathenoglobinemia particular infant up to six month of age, whose main liquid intake is powdered milk formula made up with tap water containing high concentration of nitrates. Nitrates form nitrosamines in stomach, which cause gastric cancer. From Fig.6 it is observed that, the entire sample tested nitrate was within the limit for general use.

Limit of turbidity is 5 to 10 NTU. From the Fig. 7 it was found that, the turbidity value of surveyed area is within the limit. As per IS 10500 the permissible Presence of Sulphate has less effect on taste of water as compare to presence of chloride.(4) High value Of Sulphate above $500 \mathrm{mg} / \mathrm{l}$ produces bitter taste to water and exerts adverse effect on human. In the entire sample tested sulphate was within the limit for general use.

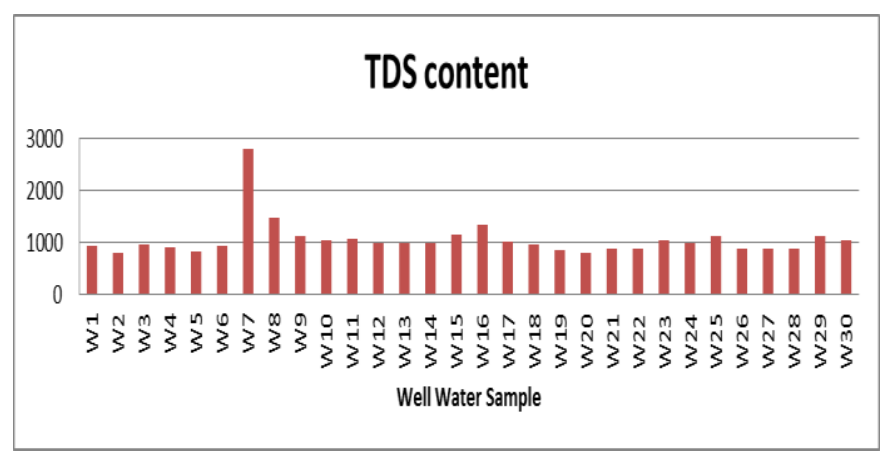

Dissolved and suspended solids be the sum of Total Solids are considered. In water sources the dissolved solid which usually predominate, consist mainly of inorganic salts, small amount of organic matter and dissolved gases. The suspended solid contents much of organic matter any increase there of rends to increase the degrees of pollution of water, if used for public health purpose. The upper limit 500ppm has been set in order to control undesirable taste and diarrhoea. The permissible limit of TDS suitable for drinking is $500 \mathrm{mg} / \mathrm{l}$ (W.H.O)(2). The Total Dissolved Solid values of water sample in study area ranged from 930 to $2800 \mathrm{mg} / \mathrm{l}$.

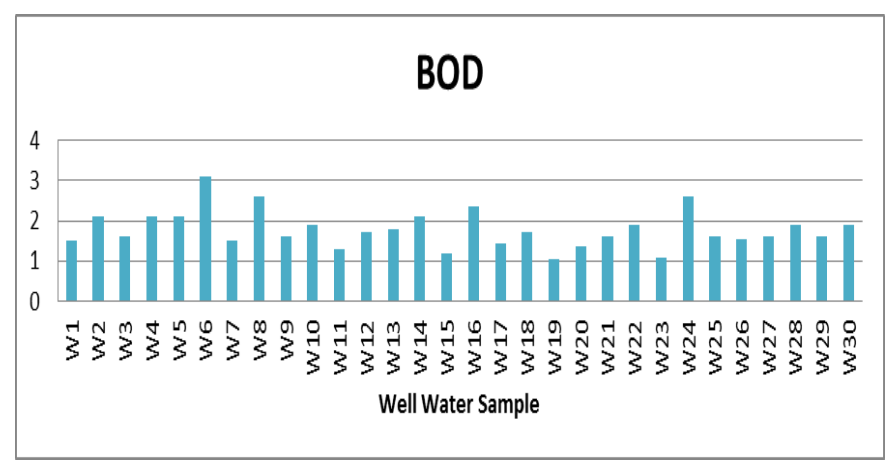

The permissible limit of iron in water is 0.3 to $1 \mathrm{mg} / \mathrm{l}$, the iron content in studied area is within the limit except Well water of ward no.10(W10). The permissible limit of fluoride content in water is 1 to $1.5 \mathrm{mg} / \mathrm{l}$ at different sampling station it were observed within the limit, as shown in Fig.

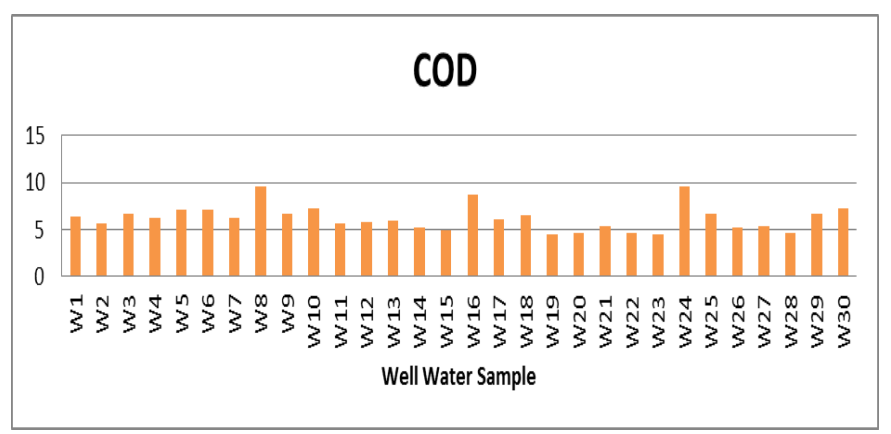

As shown in Fig.11 a, b, and c. DO, BOD, and COD values ranged from 4.8 to $7.6 \mathrm{mg} / \mathrm{L}, 1.8$ to $3.1 \mathrm{mg} / \mathrm{L} \mathrm{\&} 5.7$ to $9.6 \mathrm{mg} / \mathrm{L}$ of deferred sampling station. BOD is the amount of DO required to stabilize the biodegradable organic matter by microorganism of water under aerobic conditions. Higher BOD values attribute to the stagnation of water body leading to the absence of self-purification cycle. Increases of COD values are due to the pollution of input zones.

\section{IV- CONCLUSION}

It is very essential and important to test the water for drinking, domestic, agricultural or industrial purpose before it is used. Water must be tested with different physic-chemical parameters. Selection of parameters for testing of water is solely depends upon for what purpose we going to use that water and what extent we need its purity \& quality. Water does 
content different types of dissolved, floating, suspended and microbiological as well as bacteriological impurities. Groundwater is the most important source of water supply for irrigation, drinking, and industrial purposes. Increasing necessities of population have lead to the deterioration of surface and sub surface water. The modern urbanization \& civilization frequently discharging industrial effluent, solid waste dump \& domestic sewage. It Causes of ground water gets create health problems \& pollute. Once the groundwater is contaminated, its quality cannot be restored by removing the pollutants from the source it therefore becomes imperative to Genarally monitor the quality of groundwater and to device ways and means to protect it. So before using of water we should Analyzed analysis of some physiochemical parameters of groundwater. This may be considered as reference for the society to get Prevention about the impending deterioration of their health \& environment. Qualitatively the water in the studied area is not potable, hard \& slightly mineralized. It is suitable for domestic and irrigational use

\section{REFERENCES}

[1] Abdul Jameel A, Evaluation of drinking water quality in Tiruchirapalli, India J of Env Health, 44, 108 -112,2002..

[2] Abdul Saleem, Vijay Kumar \& Mallikarjun N. Dandigi, "In the South Ind. city of Gulbarga Correlation-regression model for physiochemical quality of well water", African J. of Environ. Science and Technology, 6(9), 353-364, 2012.

[3] Adhikary, P P, Chandrasekharan, H, Chakraborty, D, Kamble, Assessment of well water pollution in West Delhi, India using geostatistical approach Environ. Monitoring and Assessment, 154 (1- 4), 41-52, 2009.

[4] Adnan S and Iqbal J, Spatial Analysis of the Well water Quality in the Peshawar District, Pakistan, Procedia Engineering, 70, 14-22, 2014.

[5] Mogaddam \& Aghadeh N, Assessment of Well water Quality and its Suitability for Drinking and Agricultural uses in the Oshnavish Area, Northeast of Iran, J. of Environ. Protection, 1, 30-40, 2010.

[6] Agrawal V and Jagetia M, Hydrogeo-chemical assessment of ground water quality in Udaipur City, Maharashtra, India, 151-154,1997 